\title{
Intangible Cultural Heritage in China: A Visual Analysis of Research Hotspots, Frontiers, and Trends Using CiteSpace
}

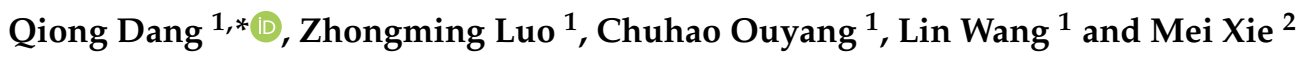 \\ 1 School of Journalism and Communication, Guangxi University, Nanning 530004, China; \\ zhongminggin@163.com (Z.L.); 18779666331@163.com (C.O.); leenw@foxmail.com (L.W.) \\ 2 School of Public Affairs and Administration, University of Electronic Science and Technology of China, \\ Chengdu 610000, China; xiemei001@163.com \\ * Correspondence: 20200012@gxu.edu.cn
}

Citation: Dang, Q.; Luo, Z.; Ouyang, C.; Wang, L.; Xie, M. Intangible Cultural Heritage in China: A Visual Analysis of Research Hotspots, Frontiers, and Trends Using CiteSpace. Sustainability 2021, 13, 9865. https://doi.org/10.3390/ su13179865

Academic Editor: Marc A. Rosen

Received: 11 August 2021

Accepted: 30 August 2021

Published: 2 September 2021

Publisher's Note: MDPI stays neutral with regard to jurisdictional claims in published maps and institutional affiliations.

Copyright: (c) 2021 by the authors. Licensee MDPI, Basel, Switzerland. This article is an open access article distributed under the terms and conditions of the Creative Commons Attribution (CC BY) license (https:// creativecommons.org/licenses/by/ $4.0 /)$.

\begin{abstract}
In recent years, the development and utilization of Intangible Cultural Heritage (ICH) has become an increasingly significant research topic. Worldwide, however, little research has been systematically and comprehensively conducted to review relevant ICH literature. The application CiteSpace was used to identify the research hotspots, frontiers, and trends in China's ICH field from 2003 to 2020. The results showed that the quantity of published literature has steadily increased throughout the respective period. Scholars and research institutions alike have shown poor cooperation whereby $\mathrm{ICH}$ protection received most of the attention. In addition, the digitalization of $\mathrm{ICH}$ is an inevitable trend in $\mathrm{ICH}$ protection and inheritance, while the combination of $\mathrm{ICH}$ and cultural industries constitutes an important approach to $\mathrm{ICH}$ utilization and communication. Hence, the ultimate goal of ICH research consists of seeking ways to achieve its sustainable development to satisfy the increasing cultural demands. Findings furthermore show that $\mathrm{ICH}$ for rural revitalization constitutes a unique research topic with Chinese characteristics. This study provides insights for scholars and practitioners worldwide to facilitate a better understanding of ICH in China.
\end{abstract}

Keywords: intangible cultural heritage; CiteSpace; research hotspots; research frontiers; research trends; China

\section{Introduction}

Ratified by UNESCO in 2003, the Convention for the Safeguarding of the Intangible Cultural Heritage has caused a significant increase in international discussions concerning the nature and value and the meaning and character of $\mathrm{ICH}$ [1]. One of its significant contributions was to emphasize that communities, groups, and individuals should extensively participate in ICH activities and/or management [UNESCO], which differs from the traditional "state-driven" operations [2]. Blake [3] asserted that the 2003 Convention has provided a "new paradigm" in safeguarding ICH as a pluralistic participation model for cultural communities, groups, and individuals. Moreover, cultural communities were placed closer to the centre of safeguarding [4], aiming to reduce the absolute power of the state in protecting and identifying ICH. Although the text of the 2003 Convention admits a new role for social actors, the connotations regarding "community" and "participation" are interpreted in various ways due to differences in the political, economic and cultural systems across countries [5]. Therefore, the concept of community still remains vague in the 2003 Convention text. So far, numerous countries have signed it, including China. In China, however, it is the government that plays a dominant position in the field of ICH. In order to adhere to the content of the 2003 Convention, the Chinese government has gradually adjusted relevant cultural policies to appropriately decentralize the power afforded to communities within ICH.

Since then, the significance of safeguarding ICH has been internationally recognized, and a significant body of valuable research achievements has emerged around the topic of 
safeguarding ICH [6-11], in particular in countries such as the United States, the United Kingdom, Spain, France, Italy, and China. A significant aspect of these studies is related to ICH's potential contribution to local society and economy. ICH-related tourism, such as festivals and handicrafts, is normally recognized as a traditional and common method that can encourage certain economic and social benefits [12,13]. However, overtourism can potentially disturb people's living habits and damage the authenticity of $\mathrm{ICH}$ as well as the natural environment [14-16]. In recent years, the integrated development of ICH and cultural creative industries, such as fashion and design, has appeared as a new trend in ICH practice and research. The application of cutting-edge technology is another relevant and significant aspect which differs from traditional technologies used to document and store ICH [17]. Advanced digital technology, such as virtual reality, can be used to provide visitors with an immersive and present experience while better preserving and disseminating ICH. For example, Selmanović et al. [18] demonstrated that the Mostar Old Bridge APP based on 3D VR can provide users with a more genuine feeling of immersion and presence compared with web-based APP. In addition, ICH is vital for maintaining cultural diversity and ensuring the sustainability of culture [4], with sustainable development forming a significant goal of ICH development. Relevant studies on ICH and sustainability have focused on the environmental, tourism, and socioeconomic practices of ICH in sustainable development [19,20]. For example, Zhang G. et al. [21] illustrated that cultural identity significantly influenced tourists' consumption intention, thereby affecting ICH tourism's sustainability.

China is a country with abundant ICH resources, including traditional handicrafts such as the making of Xuan paper, the Dragon Boat Festival, and Mazu beliefs and customs. So far, a total of 42 items of China's ICH have been included in the Representative List of the Intangible Cultural Heritage of Humanity [22]. Significantly, the Chinese Kun Qu opera was first recorded in it in 2001, marking the entrance of Chinese ICH onto the world stage. In recent years, scholars have shown their considerable concerns about China's ICH research. For example, Maags and Holbig [23] conducted a comparative analysis to examine the power relation between the elite and popular players in implementing "the Convention for the Safeguarding of the Intangible Cultural Heritage" in China. They found that its implementation strengthened the power asymmetry between them and the elite holding a dominant position in this process. Differing from Maags and Holbig's research, Massing [24] discussed, through interviews, the safeguarding of ICH by means of the theme park in the Li ethnic minority in Hainan. In addition, Skowron-Markowska and Nowakowska [25] took the Shaolin Temple and Chenjiagou Village in China as examples to explore the issue of the authenticity in the process of ICH commercialization. Their research illustrated that, to a large extent, martial art tourism has diminished in authenticity, while the authenticity in the Shaolin Temple practice showed some relevant differences in comparison, as included in the UNESCO documents. These studies conducted through qualitative methods have enriched the international ICH research. However, they have only focused on certain specific aspects of ICH research in China and have fallen short of a systematical and holistic review of China's ICH. Therefore, this study aims to conduct a bibliometric analysis of China's ICH literature, which will help readers quickly understand the knowledge structure, the main domain, and the latest developments in ICH research.

Bibliometrics, first proposed by Pritchard in 1969, entails the application of mathematical and statistical methods to objectively analyze the nature of the spatial distribution of scientific literature in a certain period and within a specific field [26,27]. It can be used to analyze the distribution of authors, citations, institutions, keywords, and topics in the literature, and therefore evaluate the development status of a scientific field and forecast its future development [28]. In recent years, bibliometric analysis as a quantitative method has generally been used in assessing massive academic outputs with the aim of revealing the structure and pattern of knowledge of a specific domain. So far, it has been widely employed in various fields such as tourism, economics, pedagogy, psychology, management, agriculture, and forestry. For example, a bibliometric analysis conducted by 
Bañales-Seguel et al. [29] used CiteSpace software to identify main research interests, as well as examine the core authors and other aspects of knowledge structures within literature concerning the Mapuche and Wallmapu in Chile. In addition, unlike most other manual review techniques, bibliometric analysis is more efficient in reducing bias or subjectivity in the process of analyzing and reviewing literature data.

The current study applied bibliometric analysis using CiteSpace software to systematically review Chinese ICH literature published between 2003 and 2020. It attempted to solve the following issues in the context of China: (1) represent the numbers of ICH publications; (2) illustrate the distribution and collaboration of authors and research institutions; (3) confirm the research hotspots and explore their evolution from 2003 and 2020; and (4) identify research frontiers and research trends.

\section{Materials and Methods}

This section addresses the following questions: (1) the selection of the analysis tool; (2) the data collection procedure; (3) the parameters and analysis path; (4) and the main metrics in the analysis.

\subsection{Selection of Analysis Tool}

CiteSpace software, a knowledge visualization tool used mainly in bibliometric analysis, is capable of objectively processing massive amounts of scientific literature data as well as visualizing relevant information [30-32]. It was developed by Professor Chen Meichao and his team from Drexel University and runs in a Java environment. This study employed CiteSpace software as an analysis tool based on several considerations. First, we compared CiteSpace with other knowledge visualization software (e.g., Bibexcel, Gephi, Pajek, VOSviewer) applied in bibliometric analysis, and found CiteSpace to be more commonly applied due to its extensive document sorting and mapping functions. Second, it can be accessed for free and is programmed to recognize Chinese characters. We can use it to conduct co-citation analysis, co-occurrence analysis, cluster analysis, and keywords burst analysis [31] in support our study. In addition, we found that one of its most prominent functions consists of assisting scholars in investigating knowledge structure and research hot spots, detecting the progress and evolution of research topics, and identifying research frontiers and trends in the relevant knowledge domain [30].

\subsection{Data Collection Procedure}

Table 1 presents the data collection procedure of this study. Data were retrieved on 15 February 2021 from the CSSCI database (Chinese Social Science Citation Index) of the CNKI database (China National Knowledge Infrastructure) and covered all ICH-related literature from January 2003 to December 2020. This study selected the CSSCI database based on two main considerations: (1) The CNKI is a foremost Chinese academic database in China, and (2) the CSSCI database (like the Web of Science core collection database) as a sub-database of CNKI lists only high-quality articles. This study selected 2003 as a starting point because this was the year in which the first academic ICH paper was recorded in the CSSCI database.

As for the retrieval criteria, the title "intangible cultural heritage," or its abbreviation "Feiyi" in Chinese, were each used with accurate matching to retrieve relevant literature, yielding a total of 2956 publications. Furthermore, we manually eliminated the possible interference of irrelevant literature (see Table 1). Only peer-reviewed quantitative and qualitative published articles concerning ICH were selected. Ultimately, 285 publications were removed and a total of 2671 publications were selected as the research target. All the selected publications concerning ICH were processed in CiteSpace, V. 5.7. R5 (https: / / citespace.podia.com/download, accessed on 14 March 2021) in March 2021. 
Table 1. The data collection and analysis protocol.

\begin{tabular}{|c|c|}
\hline Research Protocol & Retrieve Results and Contents \\
\hline Research Database & CSSCI \\
\hline Language & Chinese \\
\hline Publication type & All types \\
\hline Year span & January 2003-December 2020 \\
\hline Retrieval criterion & Title $=\mathrm{ICH}$ or abbreviation "Feiyi" in Chinese \\
\hline Exclusion criteria & $\begin{array}{l}\text { Meeting abstracts, editorial materials, book chapters, book reviews, proceedings } \\
\text { meet-ing papers, letters, conference notices, brief introductions of some research } \\
\text { centers and profile interviews }\end{array}$ \\
\hline Inclusion criteria & Peer-reviewed quantitative and qualitative published articles concerning ICH \\
\hline Number of samples & 2761 \\
\hline Data analysis & CiteSpace, V. 5.7. R5 \\
\hline Analysis paths & Co-network analysis, co-occurrence analysis, a noun-term burst analysis \\
\hline
\end{tabular}

\subsection{Paths of Analysis}

The parameters were set in advance before processing the data: (1) the node type was selected according to the corresponding analysis; (2) the time slicing happened from 2003 to 2020; (3) the length of per time slice was " 1 "; (4) the threshold selection criteria were set for the top 25, which means extracting the top 50 data of each time slice; and (5) pruning was set as minimum spanning tree. The remaining parameters were set to default settings.

After setting the parameters, CiteSpace software was used to conduct the three primary paths of analysis for the purpose of solving the research questions. The respective time span was from 2003 to 2020. The first path consisted of the co-network analysis, offering a deeper understanding of the whole research status, including the distribution and cooperation between authors and institutions. This analysis generated a co-author network and coinstitution map. The second path was the co-occurrence analysis, based on the analysis of keywords. According to keyword analysis, this study obtained a keyword co-occurrence map, a time-zone map, and a clusters of knowledge map to confirm research hotspots, detect the evolution of research hotspots, and clarify research frontiers. The third path consisted of a noun-term burst analysis, which showed whether keywords rapidly changed in a short period of time or whether they dramatically increased in number, emphasizing the abrupt change of keywords [33,34]. This can be used to classify the most active domain of research in a certain period and to predict relevant research trends.

\subsection{Main Metrics in Bibliometric Analysis}

After the CiteSpace analysis, three main metrics (i.e., betweenness centrality, silhouette, and modularity) were used to explain and describe the visualized knowledge map. Betweenness centrality refers to the ratio of the shortest path passing through a point, connecting the two points in the network to the total number of shortest path lines between those two points $[28,35]$. In a knowledge map, a node with a high centrality plays a prominent role in the communication between other nodes. Keywords with high centrality $(>0.1)$ indicated a pivotal research domain and were presented with purple rings [36]. The modularity $(\mathrm{Q})$ value and the mean silhouette $(\mathrm{S})$ value were mainly used to measure the clustering map. The $Q$ value represented the degree of modularity, ranging from 0 to 1 [30]. When it was greater than or equal to 0.3 , this indicated that the modularization of the network was significant. Meanwhile, as the value of $Q$ increased, the clustering effect of the network improved. Silhouette (S) measured the homogeneity of networks. The range of the $S$ value was situated between 1 and -1 [30]. When it was larger than or equal to 0.5 , it demonstrated that the result of clustering was reasonable. When the $S$ value exceeded 0.7 , the result of the cluster proved to be trustworthy, with homogeneity increasing as $S$ moved closer to 1 . Subsequent paragraphs discuss the results of research in combination with the key authors' literature in China. 


\section{Descriptive Statistical Analysis of the Research Literature in the Field of ICH in China}

This part includes a discussion in three sections: (1) the distribution of the selected papers, aiming to provide a better understanding of the quality of published articles; (2) a collaboration analysis of authors and research institutions, aiming to locate influential scholars and academic institutions; and (3) an identification of the relationship between authors and between academic institutions.

\subsection{Distribution of the Selected Papers in the Field of ICH}

The retrieved results show that 2761 papers concerning $\mathrm{ICH}$ were published from January 2003 to December 2020, with an average yearly publication rate of 153 . Figure 1 shows the trajectory of the selected research papers' quantity in distribution from 2003 to 2020. Three stages can be identified: the steady development period (2003-2006), the rapid growth phase (2007-2013), and the fluctuation decline phase (2014-2020).

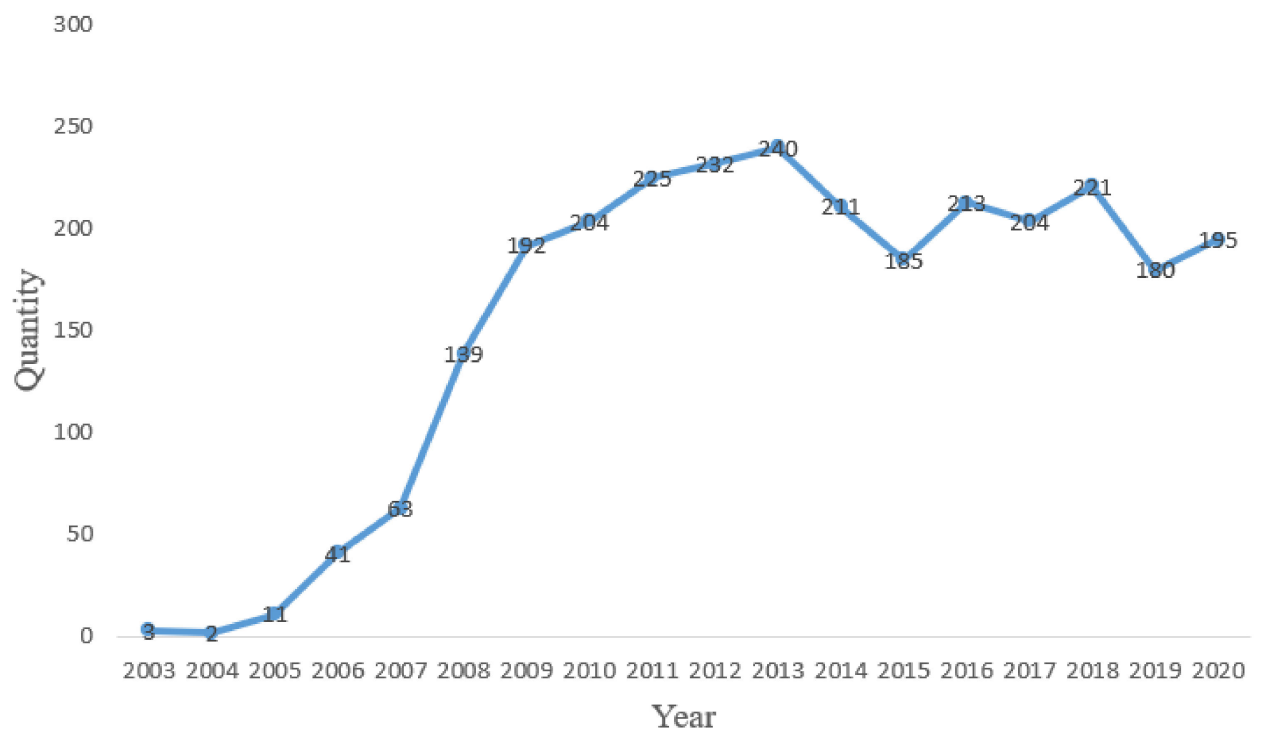

Figure 1. Distribution of selected ICH papers from 2003 to 2020 in China.

In the steady development phase, the number of the published articles remained small with merely three articles in 2003 representing the smallest proportion ( $0.11 \%)$. Moreover, the average number of papers published stood at 14 per year $(0.51 \%)$. This may be due to the fact that research on ICH was still in its infancy. Subsequently, a larger number of research achievements emerged, with a sharp increase in the number of average annual publications (193). From 2007 to 2013, the number of published articles stood at 19.3\%. The quantity of published papers reached a peak of 240 in 2003, the year with the largest number of papers due to an increased attention being paid to ICH research. In this latter stage, the quantity of published articles fluctuated. The track of the respective numbers shows a horizontal " $\mathrm{S}$ "-shaped curve, indicating an important shift from the previous periods. The average number of papers published stood at 201 per year in this stage. The number of published articles represented a percentage of 51.0\% from 2014 to 2020, indicating that research on ICH gradually matured, probably due to the formation of $\mathrm{ICH}$ research systems. The quantity of published literature increased steadily during this period, which infers continual interest and growth in the study of ICH.

\subsection{Distribution of Key Authors in the Field of ICH}

The author cooperation network map shown in Figure 2 was produced by CiteSpace, which can be used to identify authors' publication situation as well as their strength of co-operation. The map is presented by nodes and lines. Each node is labeled by the corresponding author. The size of nodes reflects the frequency of related data occurrences: the 
larger the node, the higher the frequency [30]. For example, the biggest node in Figure 2 revealed that $\mathrm{Xu} X$. published the largest number of papers. The linkage between two nodes indicates that two authors collaborated on research in the same paper. A thick line indicates a strong cooperative relationship [37]. Figure 2 shows that the lines are thin and scattered, which indicates that most of the authors conducted academic research independently and had a weak cooperative relation. Nevertheless, there are still small-scale cooperative groups. For example, Tan G.X., Zhuang W.J. and Hou X.L. had a relatively close cooperative relationship in their representative paper, "Research on Knowledge Management of Intangible Cultural Heritage Based on Linked Data" [38]. Niu A.M. and Yu D.H. wrote several articles together, such as "Development of Wushu Industry from the Angle of Cultural and Creative Industries" [39]. The relationship among these authors was usually a teacher-student as well as a collegial one.

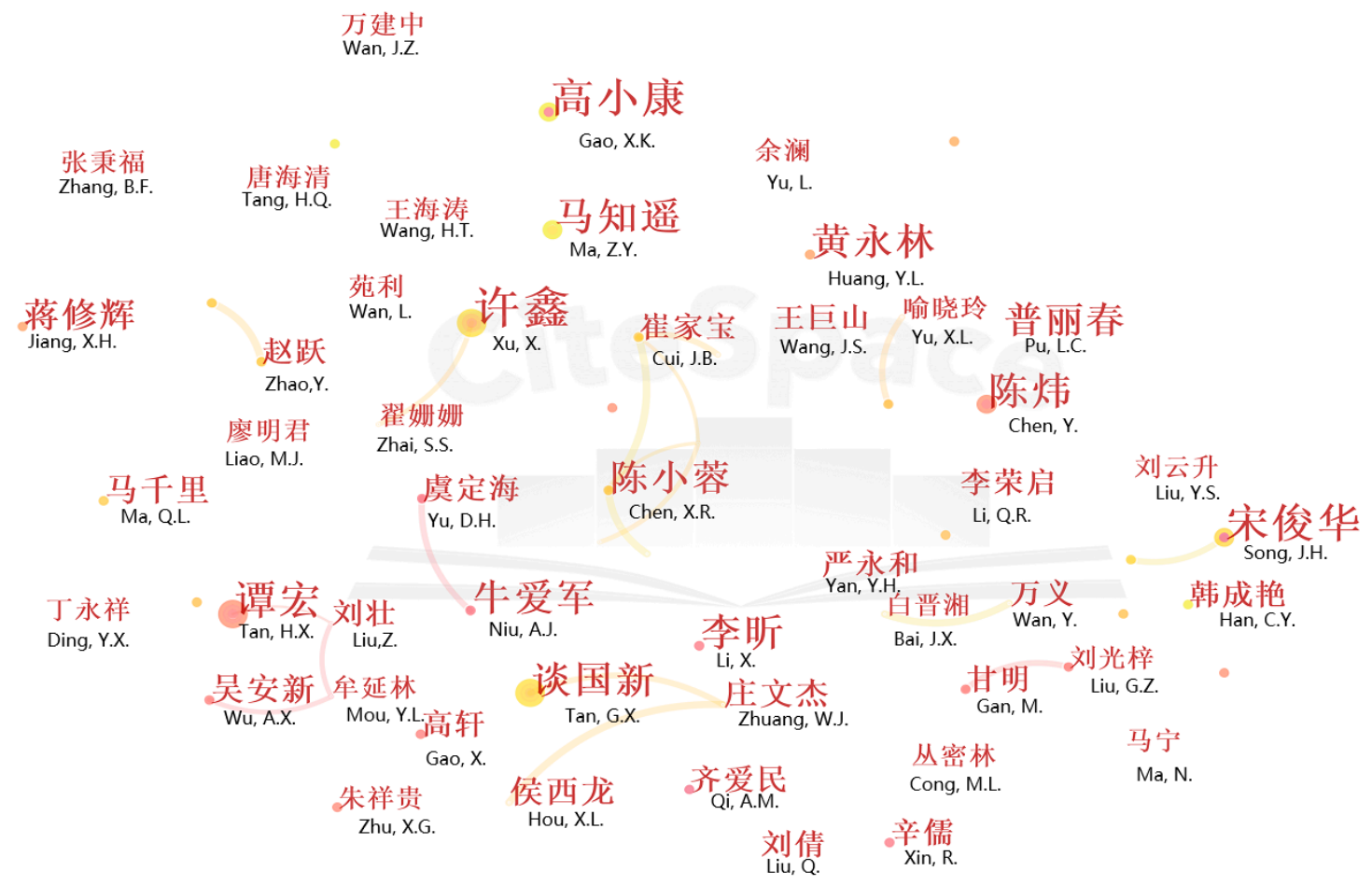

Figure 2. Author collaboration network map for ICH research from 2003 to 2020 in China (Note: The authors' romanized names were added in the map for a better understanding).

The top 10 authors in the ICH field in China were ranked according to the number of publications. In Table 2, the core authors are identified according the results of the CiteSpace software and present an overall description of the ten most prominent authors in ICH between 2003 and 2020. Their research therefore reveals the research direction and focus of the ICH field. As for the top three authors, Xu X. from East China Normal University has researched the preservation and development of ICH. Song J.H., from the Chinese Academy of Intangible Cultural Heritage of Sun Yat-sen University, has a distinctive insight into the productive protection and digitalization of ICH. His paper, "On the Characteristics of Intangible Cultural Heritage [40]," published by his team in 2006, showed the representative impact in ICH research field and was cited 229 times (the highest citation number). Gao X. K. studied the history and aesthetics of ICH and also came from Sun Yat-sen University. Significantly, they all worked in Chinese high-ranking universities and showed a keen interest in the preservation, digitalization, and esthetics of ICH. 
Table 2. Top 10 authors in ICH retrieval records in China.

\begin{tabular}{ccccc}
\hline Ranking & Name & Published Quantity & Proportion & First Year \\
\hline 1 & Xu X. & 15 & $0.54 \%$ & 2014 \\
2 & Song J. H. & 12 & $0.45 \%$ & 2006 \\
2 & Gao X. K. & 12 & $0.45 \%$ & 2007 \\
3 & Tan H. & 11 & $0.40 \%$ & 2009 \\
4 & Li X. & 10 & $0.36 \%$ & 2008 \\
4 & Ma Z. Y. & 10 & $0.36 \%$ & 2010 \\
4 & Chen W. & 10 & $0.36 \%$ & 2009 \\
5 & Niu A. J. & 9 & $0.33 \%$ & 2008 \\
5 & Huang Y. L. & 9 & $0.33 \%$ & 2013 \\
5 & Tan G. X. & 9 & $0.33 \%$ & 2017 \\
6 & Chen X. R. & 8 & $0.30 \%$ & 2017 \\
6 & Pu C. L. & 7 & $0.30 \%$ & 2009 \\
7 & Jiang X. H. & 6 & $0.25 \%$ & 2013 \\
8 & Ma Q. L. & 6 & $0.22 \%$ & 2017 \\
8 & Wu A. X. & 5 & $0.22 \%$ & 2008 \\
9 & Li R. Q. & 4 & $0.18 \%$ & 2006 \\
10 & Wang J. Z. & $0.14 \%$ & 2005 \\
\hline
\end{tabular}

Note: The proportion in the total literature. The first year indicates the time when the author first published the paper.

\subsection{Distribution of Core Institutions in the Field of ICH}

The institution network map was also generated by CiteSpace. The nodes and lines in the map have been elucidated in Section 3.2. The results are presented in Figure 3, which shows that the lines are few, scattered, and thin, illustrating a weak cooperation among ICH research institutions.

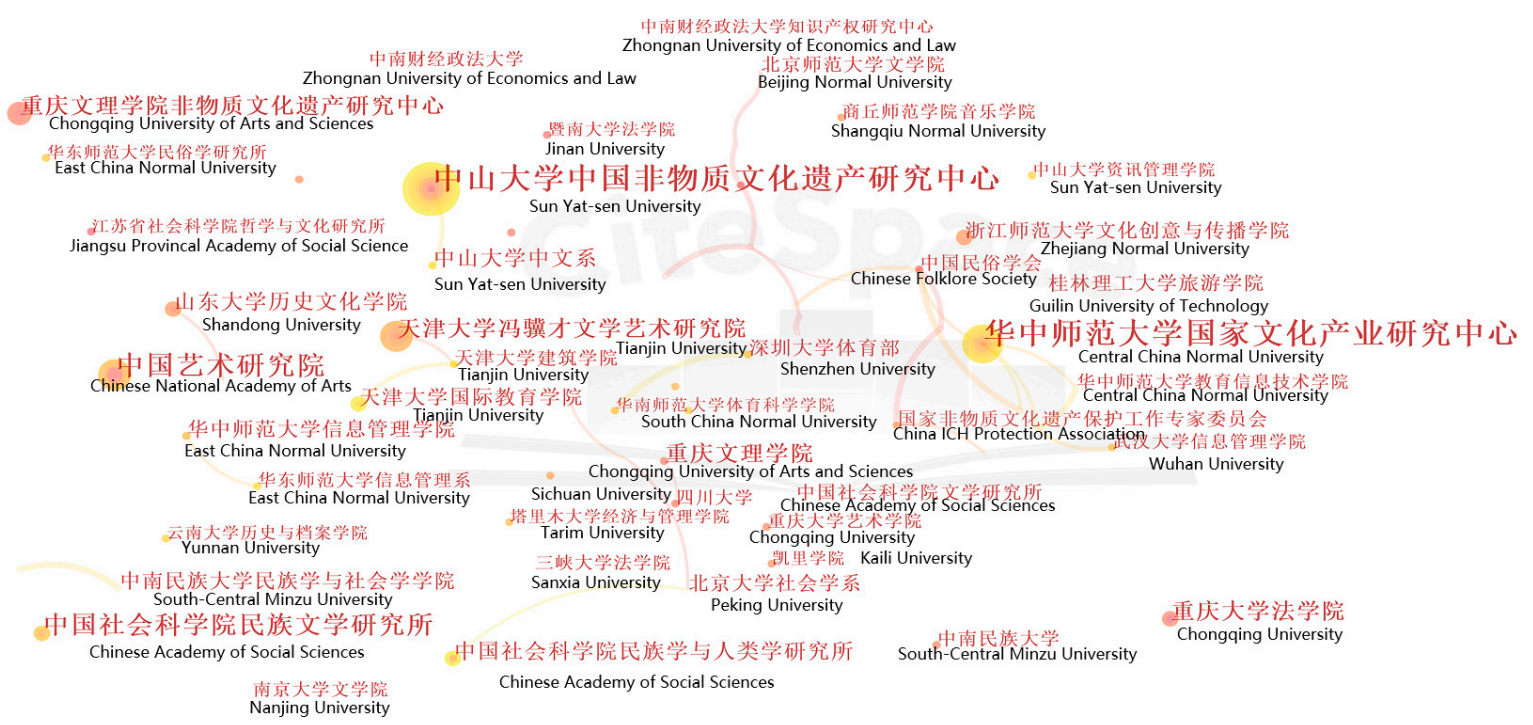

Figure 3. Institution cooperation network map of ICH research from 2003 to 2020 in China (Note: The authors added English in the map for a better understanding).

There are a limited number of cooperative relations among these research institutions. For example, Central China Normal University has a relatively close cooperation with the Chinese Folklore Society and Wuhan University. More concretely, the National Cultural Industry Research Center at Central China Normal University shoulders the responsibility of ICH research. The center focuses on research concerning the integration and innovation of ICH and digital technology, principally including digitization, big data management, and smart services pertaining to ICH resources. In addition, the Digital Cultural Heritage Research Center at Wuhan University also focuses on the digitalization of $\mathrm{ICH}$ resources, but puts more emphasis on the application of cutting-edge technology in ICH practice. 
On the other hand, the Chinese Folklore Society, a non-profit academic group of folklore scholars, mainly studies Chinese traditional rituals, folklore, and festivals from a theoretical perspective. Although they do engage in studying Chinese ICH from various angles, their ultimate aim is to maintain the sustainability of ICH resources. As a whole, Chinese academia studies ICH independently and has therefore not yet formed a wider academic framework to further optimize its research concerning ICH.

Table 3 lists the ten most productive research institutions in the field of ICH in China. Among them are eight universities and two scientific research institutes (the Chinese Academy of Social Sciences and the China National Academy of Arts). In addition, this ranking illustrates that universities constitute the core force in the study of ICH. The three respective highest ranking research institutions listed have a high reputation in China and play a leading role in $\mathrm{ICH}$ research.

Table 3. The ten most productive research institutions in ICH retrieval records in China.

\begin{tabular}{ccccc}
\hline Ranking & Institution & Records & Proportion & Year Began \\
\hline 1 & Sun Yat-sen University & 62 & $2.32 \%$ & 2006 \\
2 & Central China Normal University & 56 & $2.09 \%$ & 2011 \\
3 & Chinese Academy of Social Sciences & 51 & $1.90 \%$ & 2005 \\
4 & China National Academy of Arts & 41 & $1.53 \%$ & 2006 \\
5 & South-Central Minzu University & 37 & $1.39 \%$ & 2006 \\
6 & Tianjin University & 34 & $1.27 \%$ & 2012 \\
7 & Chongqing University of Arts and & 29 & $1.09 \%$ & 2009 \\
8 & Sciences & 19 & $0.71 \%$ & 2007 \\
9 & Chongqing University & 14 & $0.52 \%$ & 2011 \\
10 & Shandong University & 9 & $0.35 \%$ & 2005
\end{tabular}

Note: The proportion in the total literature. The first year indicates the time when the institution first published a paper.

\section{Main Research Hot Spots in the Field of ICH in China}

Chen C. [31] has argued that keyword analysis is an appropriate method in identifying popular research domains as well as the evolution of relevant research hotspots and frontiers. For the following sections, CiteSpace was used for keyword analysis, thereby generating three maps: the co-occurrence knowledge map, the time-zone view, and the cluster knowledge map.

\subsection{Main Research Interests in the ICH Field: Keywords Co-occurrence Analysis}

A co-occurrence analysis of high-frequency keywords makes it possible to reveal a field's relevant research hot spots [41], a process whereby respective keywords can also be identified as ICH research hot spots. Figure 4 presents the co-occurrence knowledge map of keywords of ICH research between 2003 and 2020.

We merged the overlapping keywords, such as 'preservation' and 'ICH preservation,' while it deleted the retrieval term. Figure 4 shows that the five highest frequency keywords with high centrality were: ICH preservation (Frequency $=472$; Centrality $=0.42$ ); inheritors $(\mathrm{F}=100 ; \mathrm{C}=0.14)$; ethnic minority $(\mathrm{F}=68 ; \mathrm{C}=0.09)$; tourism development $(\mathrm{F}=60 ; \mathrm{C}=0.08)$; and productive protection $(F=59 ; C=0.08)$. Based on both the criteria of frequency and betweenness centrality, this study extracted five research hotspots: ICH protection, inheritors, tourism development, ICH in the ethnic group areas, and productive protection. What follows is a discussion of the respective four research hotspots in combination with the key scholars' articles in China. 


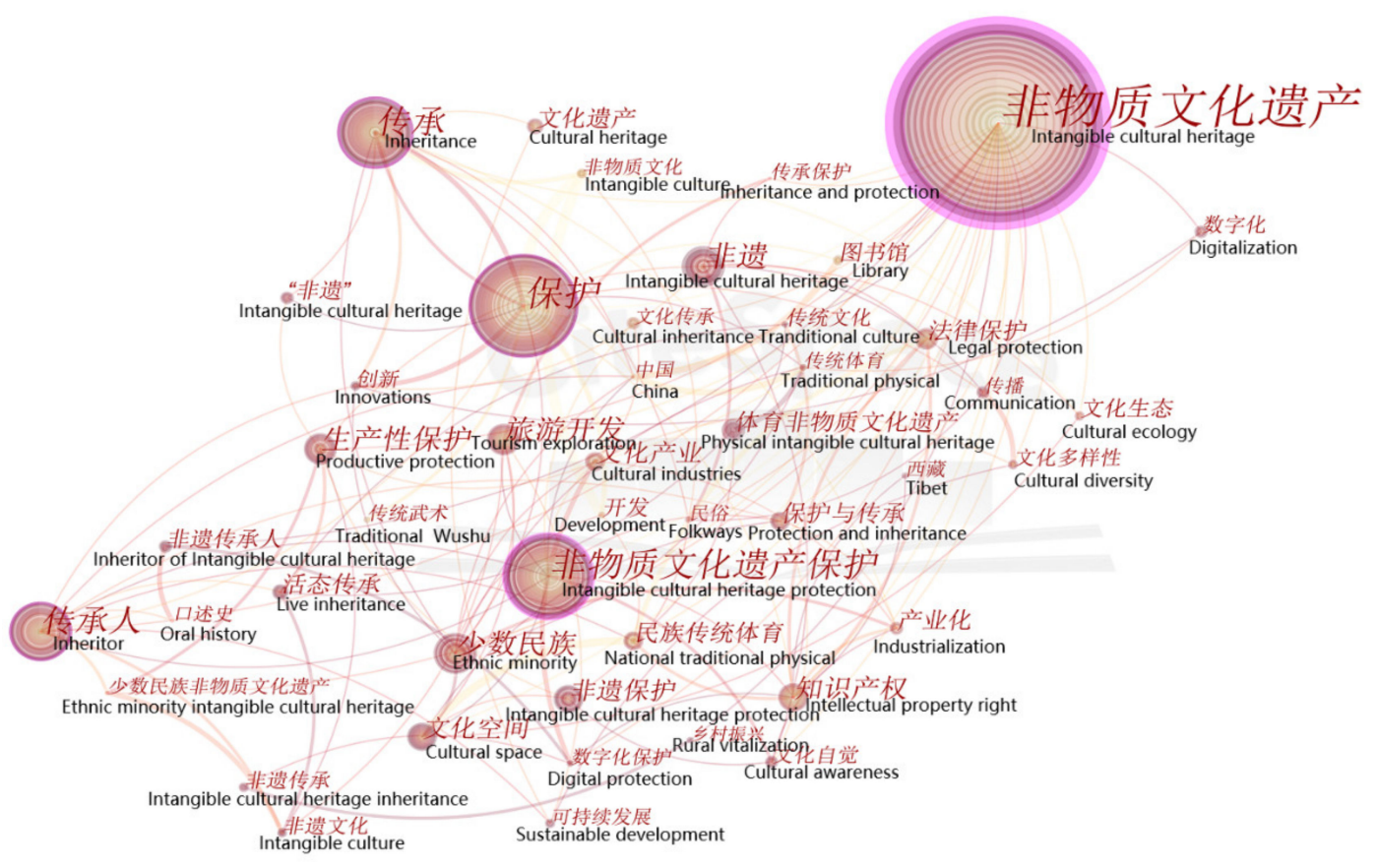

Figure 4. Co-occurrence knowledge map of keywords of ICH research in China (Note: The authors added English in the map for a better understanding).

\subsubsection{Research on ICH Protection}

The ultimate goal of ICH protection research is to maintain the sustainability of ICH resources. Thus, this research hotspot focused on the way to protect ICH resources. Legal protection and digital protection were recognized as the two most popular methods in ICH research. In terms of legal protection, it was the most authoritative protection method due to the top-down management approach in China [42]. Significantly, the ICH list and inheritors system, as well as the system of the national eco-cultural protection zone, were the three most important ICH policy measures. However, these policy measures were not well implemented as they remained vague and incomplete. For instance, Duan C. and Sun Y. [43] found that in the process of the ICH list confirmation, the relevant policy ignored the participation of cultural owners. In order to tackle the issue, Huang T. and Zheng W.Q. [44] suggested that the local people's right to know and decision-making should be expanded in the protection work of ICH.

In addition, digital technology contributed to the protection of endangered ICH resources. For instance, it was used at the Riverside Scene at Qingming Festival in the form of a virtual simulation animation [45], which attracted a great number of young visitors. In addition, digitalized ICH resources can be stored in a digital museum and library and displayed through a digital platform (e.g., the internet and various applications). Among digital protection methods, it should be stressed that building ICH digital archives constitutes the most common way.

\subsubsection{Research on ICH Inheritors}

Inheritors are the main subject of ICH protection and bear the responsibility of protecting and inheriting ICH. This implies that, to a large extent, protecting inheritors is the premise of protecting ICH for living inheritance [46]. Nevertheless, the traditional 'master-prentice' mode of training proved to be outdated [46]. Therefore, the focus of such research is to seek the innovative measures to foster high-quality ICH inheritors. Ma $\mathrm{N}$. [47] proposed that school and community education were recognized as one of the most significant measures to train a great number of inheritors. However, Ma, N.also stressed that the role of governments should not be ignored in the process of training $\mathrm{ICH}$ 
inheritors. She furthermore suggested that the government adopt the administrative means to establish an access and supervision mechanism for representative inheritors in an effort to ensure that they enjoy the same treatment as national civil servants.

\subsubsection{Research on ICH Tourism Development}

Tourism development is not only an essential practice of ICH development, but also a traditional way of using ICH. This research hotspot focused on the development value, development mode, and the problems existing in the development of ICH tourism. The social-economic value of ICH tourism has been widely discussed. A significant body of studies illustrated that, to a large extent, ICH tourism generated a significant number of job opportunities for local residents [48-50]. Moreover, it increased the local government's revenue and, therefore, drove the development of the local economy [51]. However, a limited number of scholars have pointed out that overtourism has caused a series of problems, such as environmental damage and pollution, and the degradation of the authenticity of ICH [52]. Moreover, the ICH tourism development model mainly included the establishment of ICH theme parks and museums, festival tourism, and experience tourism. Among them, ICH experience tourism was widely discussed because it could provide personalized services and meet the tourists' emotional needs. More importantly, ICH tourism involved various stakeholders, such as communities, local governments, and enterprises. Therefore, how to coordinate and balance their interest relationship is an important topic needed to be further discussed.

\subsubsection{Research on ICH in Ethnic Minority Areas}

ICH in ethnic minorities has become a research hotspot, mainly because it is of great significance in the strengthening of national identity, maintaining cultural diversity, and in promoting local socioeconomic development [53]. This research hotspot emphasized the issues facing the progress of ICH protection and utilization within the minorities of the Yunnan, Guizhou, Guangxi, Hainan, and Heilongjiang provinces. This suggested that a poor natural environment and climate, as well as a lack of funds, formed the main factors hindering the practical work of ICH protection [54,55]. In order to overcome these problems, Wang X.M. and Li H. [56] suggested setting up an online platform to record and display $\mathrm{ICH}$ while encouraging people to visit $\mathrm{ICH}$ websites in an effort to reduce the pressure on the local environment. Moreover, Li L.Y. and Zeng Y.C. [57] illustrated that ethnic minorities in Southern Guizhou were able to develop festival tourism without damaging the local environment for the sake of making profit. Significantly, most studies showed a positive impact on ICH tourism by ethnic groups and highlighted that this could, to a large degree, increase local revenue.

\subsubsection{Research on Productive Protection}

The concept of productive protection was first proposed in 2010. It refers to the transformation of ICH resources into productivity-based products by means of their production, circulation, and sales [58], which revealed that it was also a way to protect economic benefits. This research hotspot was divided into two dimensions. The first one focused on the scope of the application of productive protection. For example, Wang J.Y. [59] argued that it could be applied in the field of traditional handicrafts, traditional art, and traditional medicine. However, Li Y. L. and Zeng Y.C. [57] disagreed and considered that it should be used in the field of ballads, dances, and traditional festivals. So far, its scope of application still remains undefined and needs to be further explored. In addition, another research focus consisted of investigating ways to correctly treat the economic value of productive protection. An opinion widely accepted was that the premise of productive protection was to maintain the "authenticity" and "aboriginality" of ICH [60], which implied that overemphasizing its economic value in the process of productive protection should be avoided. 


\subsection{The Evolution of the Research Hotspots in the Field of ICH: Keywords Time-Zone Map Analysis}

The time-zone produced by CiteSpace focuses on representing the evolution of research hotspots from a time dimension in the ICH field. According to the high-frequency words shown in Figure 5, this study divided the evolution process of ICH research into four stages. Each stage was discussed in combination with the representative articles and key events at that time.

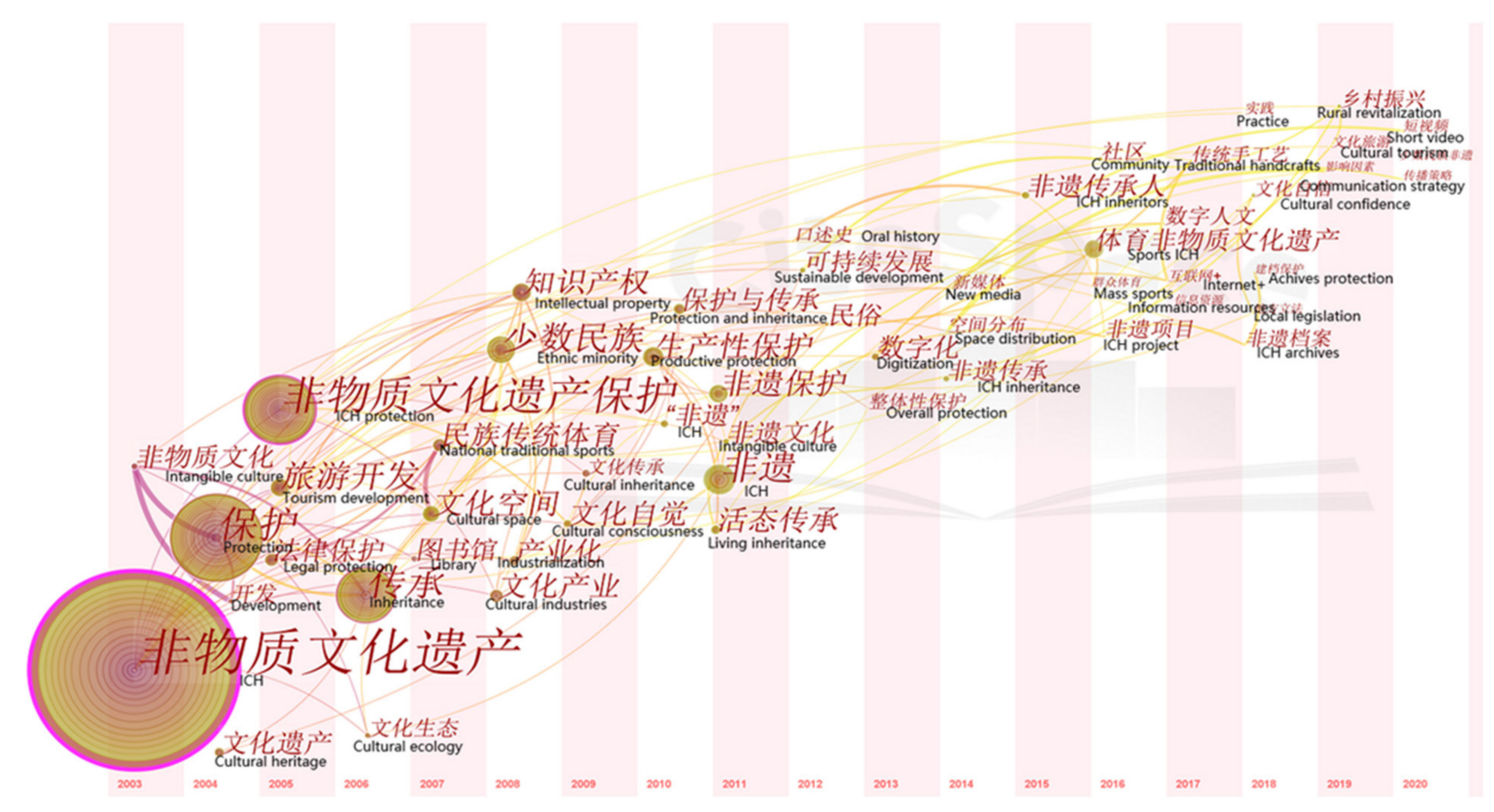

Figure 5. The time-zone view of ICH research from 2003 to 2020 in China (Note: The authors added English in the map for a better understanding).

\subsubsection{Stage 1 (2003-2007): Studies on Measures for ICH Preservation and Inheritance}

Figure 5 shows that the relevant high frequency keywords in stage 1 mainly include $\mathrm{ICH}$, protection, inheritance, tourism development, legal protection, and cultural space. This revealed that ICH protection and inheritance formed the most remarkable characteristic of this period. This could be due to a variety of reasons. In 2001, the Chinese Kun Qu opera was first recorded in the 'Representative List of the Intangible Cultural Heritage of Humanity,' marking the entrance of Chinese ICH onto the world stage. Moreover, "The Convention for the Safe-guarding of the Intangible Cultural Heritage" was adopted by the UNESCO General Conference in 2003. Influenced by both the Convention and western theories concerning ICH, scholars in China started to reconsider the safeguarding of ICH. One of the more urgent discussions was whether ICH resources could be profitable or not. Chinese academia eventually reached a consensus that the correct utilization of ICH resources for making profits could, to a large extent, promote the safeguarding of $\mathrm{ICH}$. This constituted a major breakthrough in relevant research emphasis on the non-profit characteristics of ICH. In addition, the Chinese government instituted related policies to encourage ICH tourism development, such as the guidelines set out in "Opinions on Strengthening the Protection of Intangible Cultural Heritage of China" [61].

\subsubsection{Stage 2 (2008-2012): Studies on Development and Utilization of ICH Resources}

Figure 5 shows that the relevant high-frequency keywords in stage 2 include ethnic minority, intellectual property, productive protection, protection and inheritance, living inheritance and cultural industries. This indicates that the integrated development of 
$\mathrm{ICH}$ and cultural industries (i.e., industrialization of $\mathrm{ICH}$ ) emerged in this stage. Two possible explanations can be offered for this. On the one hand, the principal contradiction in China during this period was 'the ever-growing material and cultural needs of the people and backward social production' [61]. In order to satisfy these cultural needs, greater attention was paid by scholars to exploring the social-economic value of ICH. Among other scholars, Liu L.L. [62] considered that ICH constituted important cultural capital for the development of cultural industries due to its scarcity and non-renewability. In the process of ICH industrialization, productive protection and intellectual property became two popular research domains. On the other hand, a lack of funds was the primary factor in protecting endangered ICH. In order to handle this issue, a significant body of scholars demonstrated that industrialization of ICH as an innovative development model could facilitate the development of the local economy $[50,62,63]$.

\subsubsection{Stage 3 (2013-2017): Studies on Digitalization and Inheritance of ICH}

The relevant high-frequency keywords included digitalization, new media, ICH inheritance, inheritors, digital humanity, sports $\mathrm{ICH}$, internet plus, folk custom, and information source (see Figure 5). This revealed that digital technology formed a significant factor affecting ICH development. There are two possible explanations for this. First, digital technologies had already made a major breakthrough in the ICH practice and have been widely used in the field of traditional arts, music, sports, and festivals. Empirical results by He X.L. and Niu J.M. [64] demonstrated that 3D digital technology can reproduce the traditional craft of the Duan ink slab. Moreover, these technologies have changed the traditional one-way communication model of ICH. A good example is that audiences can easily access ICH digital images and videos through the internet while providing feedback, making it a two-way communication process [65]. In addition, relevant policies drove the application of digital technology in the field of ICH, such as the "Revitalization Plan of Chinese Traditional Crafts" [66] and the 2015 "Guiding Opinions of the State Council on Vigorously Advancing the 'Internet Plus' Action" [67]. This illustrated that digital technology has become an effective measure to protect ICH resources in theory as well as practice.

\subsubsection{Stage 4 (2018-the present): Studies on ICH for Rural Revitalization}

The high-frequency keywords for this period included cultural confidence, rural revitalization, and cultural tourism (see Figure 5). A new research hotspot (ICH for rural revitalization) appeared in this stage mainly due to the influence of relevant policies. Essentially, rural revitalization constituted a typical term with Chinese characteristics proposed by China's central government in 2017 in an attempt to alleviate poverty. Soon afterwards, it has attracted extensive attention in Chinese academic circles. Scholars increasingly quoted the term "rural revitalization" in their ICH research, and their studies focused on ICH for rural revitalization from a cultural and social-economic perspective. In recent literature, the research focus was on the utilization of traditional handicrafts and cultural tourism in rural areas.

\section{Research Frontiers and Trends in the Field of ICH in China}

\subsection{Research Frontiers of ICH in China: Cluster Map Analysis}

The cluster analysis was carried out using CiteSpace to group keywords into themes. The results are presented in Figure 6, containing a total of 14 clusters with each cluster size being determined by the numbers of articles in a cluster.

Figure 6 illustrate that Clusters $\# 0, \# 1, \# 3, \# 4, \# 6, \# 9, \# 11$, and \#13 formed a core research topic of ICH protection and inheritance, while clusters \#5 and \#7 involved ICH inheritors. The remaining clusters include ICH protection and inheritance, ICH inheritors, intellectual property rights, tourism development, sports $\mathrm{ICH}$, cultural ecology, and rural culture. In combination with the five research hotspots discussed in Section 3.2, it was found that ICH preservation, inheritors, and tourism development constituted both research hotspots and 
frontiers. Therefore, the four research frontiers were determined as intellectual property rights, sports ICH, cultural ecology, and rural culture. What follows here is a discussion of the four research frontiers in comparison with the representative literature with high-cited numbers in China.

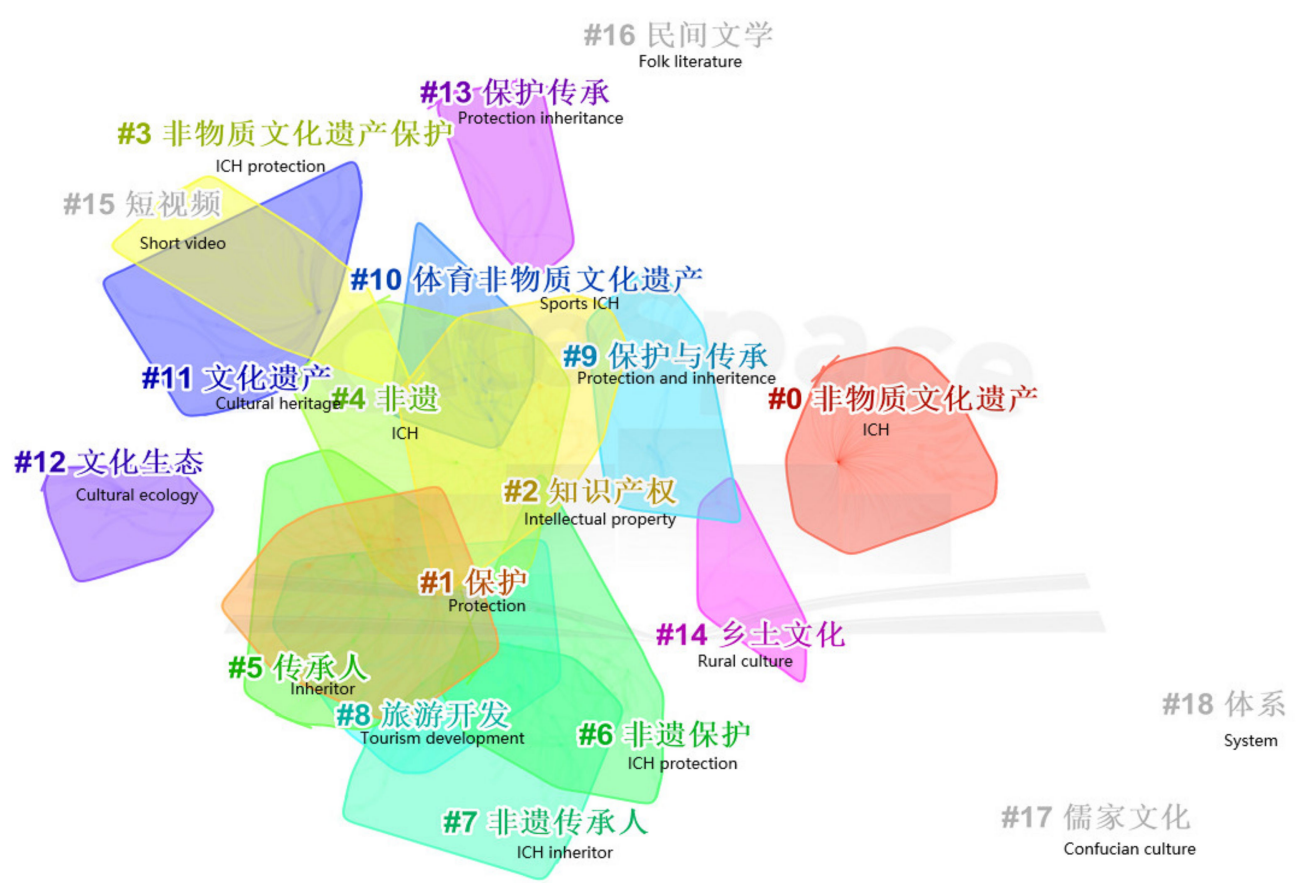

Figure 6. Knowledge map clusters in ICH research in China (Note: Modularity Q = $0.6394(>0.3)$ indicate that the cluster map is significant. The value of Silhouette $=0.9143(>0.7)$ reflects the results are trustworthy. The authors added English in the map for a better understanding).

\subsubsection{Cluster \#2: Intellectual Property Rights}

The term "intellectual property" belongs primarily to legal terminology. In recent years, it has become a popular research domain in the field of ICH. Liu X.N. initially considered that there was an irreconcilable contradiction between the public and private attributes of $\mathrm{ICH}$, and that protecting ICH intellectual property may encroach upon public attributes of ICH [68]. However, a significant body of scholars subsequently criticized this opinion and emphasized that the protection of intellectual property can, in turn, better protect the cultural property rights of owners of $\mathrm{ICH}$, and therefore realize $\mathrm{ICH}$ sharing [69-71]. Recently, intellectual property violation has turned into a significant problem confronting ICH development, rendering the protection of intellectual property an urgent matter. In order to handle this issue, Jie X.N. et al. [69] suggested to clearly define the subject of ICH rights in relevant intellectual property policies and to improve the intellectual property legislation system concerning ICH. In addition, protecting ICH intellectual property in the digital era is still an issue in need of further exploration.

\subsubsection{Cluster \#10: Sports ICH}

The concept and connotation of sports ICH has been deeply and thoroughly discussed, with Liu X.S.'s [72] definition having been widely accepted. It refers to a traditional sports resource created and accumulated in the long process of history and containing fitness value, entertainment value, educational value, aesthetic value, and economic value. In addition, sports ICH in different regions shows different characteristics, with scholars exhibiting a particular interest in the space distribution of sports ICH. For example, Yin D. et al. [73] found that it was mainly distributed in the eastern and central regions and less so in the western ones. The natural geographical environment was the key factor that influenced the space distribution of sports ICH. In recent years, a number of recent 
studies investigated the protection and utilization of sports ICH in the cities located close to the 'the Silk Road Economic Belt and the 21st-Century Maritime Silk Road' (a global infrastructure development strategy by the Chinese government involving nearly 70 countries and international organizations) $[74,75]$. These studies illustrated that Wushu (e.g., Wing Chun boxing), sports games (e.g., Chinese chess), and wrestling played a positive role in international cultural exchange.

\subsubsection{Cluster \#12: Cultural Ecology}

There is an equally close relationship between cultural ecology and $\mathrm{ICH}$, with the former being the building stone for what is generally labelled as 'intangible cultural heritage,' and with significant ICH development conducive to the maintenance of cultural ecology. Benign cultural ecology promotes the inheritance of ICH. Yet, the cultural ecology of ICH has recently been damaged in China due to a lack of public awareness vis-à-vis cultural protection [76]. Therefore, considerable efforts have been undertaken to seek methods in order to realize the harmonious development of ICH and cultural ecology. For example, Yang S. S. [76] argued that it was helpful to establish a supervision mechanism for the cultural ecological protection of sports ICH with the participation of government departments, social organizations, enterprises, community organizations, and community residents.

ICH has been in constant change since its formation, a process in which cultural change entails adapting to the environment. In fact, local governments or residents initially neglected the protection of the cultural ecological environment while developing ICH re-sources, leading them to achieve economic development at the unfortunate cost of damaging the local cultural environment. In order to avoid a repeat situation, the Chinese Central Government introduced the concept of cultural ecology into the overall protection policy of ICH. For example, in 2019 'the Measures for the Administration of National Ecocultural Protection Zones' [77] proposed the establishment of eco-cultural protection zones, aiming at the regional and overall protection of ICH. Since the 1980s, experts and scholars in China and abroad have already carried out specific research concerning eco-cultural protection areas with national characteristics, while also putting forward the protection principles of liveness, integrity, sustainability, and authenticity. The term, 'cultural ecological protection zone' was prompted by the deterioration of the regional ecological environment and aimed to realize the sustainable development of ICH. In 2007, China's first national-level 'Southern Fujian Cultural and Ecological Protection Experimental Zone' was established, illustrating that the construction of a cultural ecological protection zone in China had developed from theoretical research into the stage of practical exploration.

\subsubsection{Cluster \#14: Rural Culture}

ICH forms an important component of China's rural culture and is closely related to rural development and cultural construction. Yet, in the early stage of research into ICH protection, its role in local cultural and socioeconomic development was ignored. In recent literature, Huang Y. L. [78] found that most ICH projects and inheritors can be found in rural areas and were important foundations as well as endogenous powers of rural cultural development. Meanwhile, such projects have been given renewed economic and cultural significance, which goes a long way towards alleviating poverty through stimulating the innovative vitality of local culture in the historical process of Chinese rural revitalization.

\subsection{Research Trends in the Field of ICH in China}

Figure 7 represents the top 28 keywords with the strongest citation bursts extracted from ICH literature from 2003 to 2020. Based on the keywords with high-intensity citation bursts for 2020 (i.e., citations spanning to 2020), this study divided the research trends into five aspects: (1) the application of digital technology in ICH; (2) community participation in ICH protection and governance; (3) the sustainable development of ICH; (4) traditional handicrafts revitalization; and (5) ICH's role in the improvement of cultural confidence, all 
of which will be discussed here by comparing them with the representative literature of high-cited numbers in China.

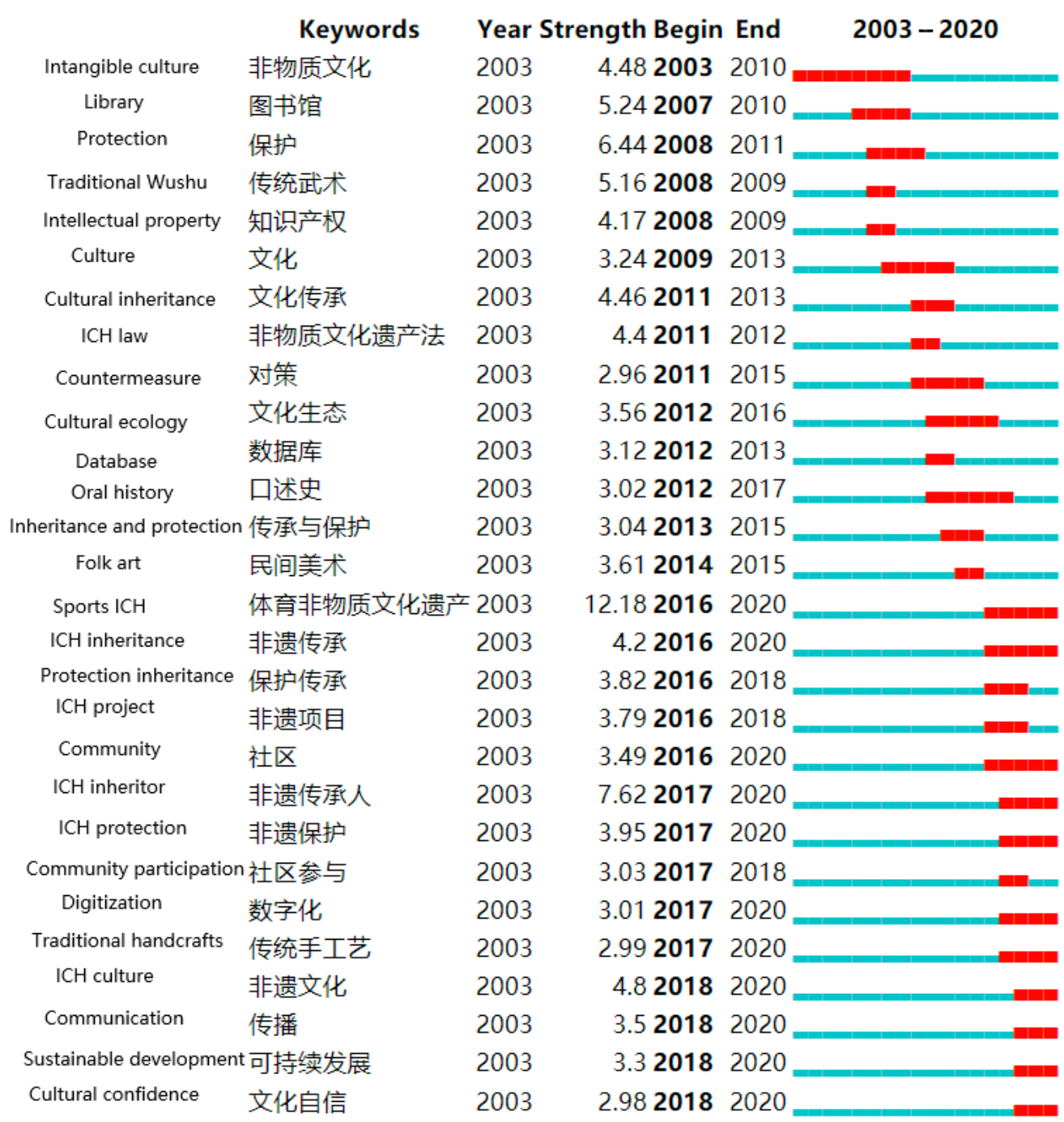

Figure 7. Top 28 Keywords with the Strongest Citation Bursts in ICH research in China (Note: The red color shows the period of detected term burst, while the blue one presents the time. The authors have included English in the map for a better understanding).

\subsubsection{Research on the Application of Digital Technology in ICH}

The research focus here was the application of the latest digital technology in the field of ICH. For instance, Qin J.Y. and Jia R. [79] found that AI technology could provide a detailed restoration of the China's cloisonné manufacturing production process and that the respective technology could therefore effectively enhance the visitors' experience. Moreover, big data changed the management mode of ICH from archives management to knowledge management [80].

\subsubsection{Research on Traditional Handicraft Revitalization}

Recently, traditional handicrafts find themselves in a delicate situation, marked by a lack of inheritors, the aging of inheritors, and weakening of its value. Therefore, scholars have sought innovative methods to promote the creative transformation and innovative development of traditional handicrafts, aiming to maintain its vitality and sustainability. For example, it was considered helpful to set up a manual experience class to teach irregular embroidery techniques (i.e., embroidery with overlapping threads in different directions) [81]. In addition, Qian Y. P. [82] discovered that the industry's respective organi- 
zation has been established with manual techniques at its core, which was subsequently responsible for the design, production, marketing, and sale of embroidery products. This illustrated that embroidery handicrafts have been successfully transformed from a cultural resource to an industry, which not only recreated the new cultural ecology of local handmade embroidery, but also made a positive contribution to local economic development. However, the industrial production of embroidery products may damage the uniqueness of traditional embroidery techniques.

\subsubsection{Research on the Sustainable Development of ICH}

In China, the first academic ICH article on sustainable development was published in 2008. Since then, $\mathrm{ICH}$ sustainable development failed to receive widespread attention in Chinese academia. Until 2015, 'Transforming Our World: the 2030 Agenda for Sustainable Development' was passed by the General Assembly of the United Nations. This indicated that, on a global scale, culture was brought into the category of sustainable development for the first time in the 2030 Agenda. Influenced by this, Chinese scholars began to reconsider the topic of ICH sustainable development. However, along with China's recent acceleration of urbanization and modernization, ICH is in danger of gradually disappearing. Scholars are therefore devoting themselves to explore more effective paths of sustainable ICH development. Qian Y.P. [83], for example, proposed that two important innovative methods for ICH sustainable development consist of developing cultural and creative products (or services) and digitalizing ICH resources.

\subsubsection{Research on Community Participation in ICH Protection and Governance}

Community participation refers to the community's participation in the protection of $\mathrm{ICH}$ and constitutes one of the core principles of ICH protection [44]. Insufficient attention has been paid to community participation in the practice of ICH protection [84-86], which resulted in more recent research having stressed relevant government involvement. In recent years, communities began attracting extensive scholarly attention, resulting in discussions on whether the community should be given priority in the process of ICH protection. Zhu G. [84] suggested that the widest possible relevant participation, as well as all concerned communities, groups, and individuals, should play a primary role in the process of protecting their ICH. Moreover, An D.M. [85] considered that negotiation and interaction were the most effective means to place communities, groups, and individuals at the centre of safe-guarding ICH. However, it is noteworthy that improper community participation could lead to communitarianism, which illustrates the importance of correctly handling community participation in the practical work of ICH protection.

\subsubsection{Research on ICH role in the Improvement of Cultural Confidence}

In a strict sense, cultural confidence is a political terminology, which usually appears in China's official documents. It has recently become a research topic in the field of ICH, which may have been partially due to the influence of official documents, such as "The Report of the 19th National Congress of the Communist Party of China" [87]. ICH protection and promotion are equally considered effective ways to enhance the cultural confidence of the nation, while deviation from the cultural identity of ICH may lead to a loss of cultural confidence. The latter, however, remains a relatively abstract concept, with current relevant research finding itself in the initial stages [88]. Moreover, although the titles of a number of studies have included the term 'cultural confidence,' the main content was often about measures to improve the protection of ICH (e.g., Cai H.B. [89]).

\section{Discussion and Conclusions}

\subsection{Discussion}

In China, the number of published articles (from 2003 to 2020) has grown rapidly since 2007, illustrating scholars' persistent interest in ICH research. However, the authors and research institutions have, at times, shown a weak cooperation. Significantly, the 
most productive authors worked in Chinese high-ranking universities, while research institutions are well-known academic institutions in China. In addition, these authors and institutions have shown a keen interest in the application of digital technology in ICH. ICH protection and inheritance were found to be research hotspots and frontiers as well as research trends, indicating that they are still a top research priority in $\mathrm{ICH}$ literature. Chinese scholars have essentially overemphasized the economic value and underestimated the humanistic value of ICH tourism [82]. This differs from other countries' research which primarily focused on the study of ICH tourism destinations as well as tourists' loyalty and satisfaction $[90,91]$. It is noteworthy that the ICH of ethnic areas became a research hotspot, mainly aiming to safeguard cultural diversity and national and local identity in China.

This study found that the evolution of research hotspots in China was mainly influenced by international ICH research, digital technologies, policies and regulations, as well as cultural demands. However, the government's policies and regulations were considered to be the core factor facilitating its evolution, which can be attributed to China's top-bottom culture system. We believe that digital technology drives the development of ICH research and provides researchers with a new research direction. In addition, the industrialization of ICH is a research phenomenon in need of further discussed. We also found that ICH for rural revitalization was shown to be a novel research domain in the fourth stage. However, we believe that this new research topic mainly covers a political veil since the Chinese government has placed ICH for rural revitalization into a prominent strategic position. Finally, we would like to emphasize that this field of research is still relatively unexplored and is in need of further in-depth study.

In terms of research frontiers, we were surprised to find that $\mathrm{ICH}$ categories such as traditional opera, drama, and sports (in particular traditional Wushu) have attracted the bulk of research attention. One possible explanation is that sports, as a form of cultural consumption, have gradually become integrated into people's daily life, thereby stressing their function as games and entertainment [75]. We found that intellectual property increasingly attracted Chinese scholars' attention, indicating an awakening of the public's legal consciousness and the continuous improvement of the legal system's concern with $\mathrm{ICH}$ intellectual property rights. In addition, cultural ecology has become a research frontier, revealing that the environment for the survival of $\mathrm{ICH}$ is deteriorating and that the public awareness of environmental protection is increasing. This study suggests that ICH's role in the construction of Chinese rural culture should be emphasized, aiming to facilitate the farmers' cultural literacy.

In terms of research trends, we found that, significantly, the community participates in the protection of $\mathrm{ICH}$, indicating that there was a shift from the centralized protection model led by the government, to the pluralistic protection model of community, individuals, cultural organizations, and enterprises. In addition, we established that sustainable development forms the ultimate goal of $\mathrm{ICH}$, while traditional handicrafts have been a pivotal approach to rural revitalization. It is noteworthy that achieving cultural confidence has become a new cultural goal in the development of ICH in China.

\subsection{Conclusions}

This study aimed to provide ICH researchers with a quantitative review of ICH literature through bibliometric analysis with the purpose of achieving a more profound understanding of how the ICH field has developed and evolved in China from 2003 to 2020. The research conclusions are largely consistent with the research conclusions of other scholars in this field. The exception, however, was that this study argued that ICH for rural revitalization constitutes a unique research topic with Chinese characteristics. Moreover, we found that the digitalization of $\mathrm{ICH}$ is an inevitable trend of $\mathrm{ICH}$ protection and inheritance, while the combination of ICH and cultural industries forms an important approach to its relevant utilization and cultural communication. Finally, this study established that the ultimate goal of $\mathrm{ICH}$ research is to seek ways to achieve ICH sustainable development so as to maintain cultural diversity and satisfy the public's increasing cultural demands. 
To our knowledge, this is the first study written in English to have systematically and holistically analyzed ICH literature based on a Chinese collection database using a bibliometric analysis method. This study furthermore aimed to provide an insight into ICH by offering valuable information for researchers to identify new perspectives on potential collaborators, hotspots, and future research directions. In addition, ICH preservation and utilization issues in China can also serve as a typical and important problem for countries with a wealth of ICH. Therefore, China's ICH preservation and utilization experiences, such as ICH for rural revitalization, may be used as a reference on an international scale, especially in developing countries with rich ICH resources and large populations.

This study does, however, count a number of limitations. It was conducted in a Chinese context and data were obtained from the Chinese CSSCI database, rendering it hard to generalize findings to other countries. Furthermore, most countries have their own database resources using different languages. It is therefore suggested that further studies would conduct a comparative analysis of the different language databases in the ICH field.

Author Contributions: Conceptualization, Q.D. and Z.L.; Methodology, Q.D.; Software, Q.D.; Validation, L.W., C.O. and Z.L.; Resources, Z.L.; Data Curation, Q.D. and Z.L.; Writing-Original Draft Preparation, Q.D.; Writing-Review and Editing, Q.D., L.W., C.O. and Z.L.; Visualization, Q.D.; Supervision, M.X. All authors have read and agreed to the published version of the manuscript.

Funding: Sichuan Key Research Base of Social Sciences- Digital Culture and Media Research Base (Project No.:19CDCM02); Talent Project of Guangxi Science and Technology Department (Project No: 2020AC19228); Young Teacher's Basic Ability Improvement Project of Universities in Guangxi (Project No.: 2021KY0006). We sincerely appreciate their supports.

Conflicts of Interest: The authors declare no conflict of interest.

\section{References}

1. Smith, L.; Akagawa, N. Intangible Heritage; Routledge: London, UK, 2008.

2. Stefano, M.L.; Davis, P. The Routledge Companion to Intangible Cultural Heritage; Taylor \& Francis: Boca Raton, FL, USA, 2016.

3. Blake, J. The impact of UNESCO's 2003 Convention on national policy-making: Developing a new heritage protection paradigm? In The Routledge Companion to Intangible Cultural Heritage; Routledge: London, UK, 2016; pp. 93-102.

4. The United Nations Educational, Scientific and Cultural Organization (UNESCO). The Convention for the Safeguarding of the Intangible Cultural Heritage. Available online: https:/ / ich.unesco.org/en/convention (accessed on 23 October 2003).

5. Deacon, H.; Bartolotto, C. Charting a Way Forward: Existing Research and Future Directions for ICH Research Related to the Intangible Heritage Convention', The First ICH Researchers' Forum of 2003; Convention International Research Centre for Intangible Cultural Heritage in the Asia-Pacific Region (IRCI): Osaka, Japan, 2003; pp. 31-41.

6. Akagawa, N.; Smith, L. Safeguarding Intangible Heritage: Practices and Politics; Routledge: London, UK, 2018.

7. Foster, M.D. UNESCO on the Ground. J. Folk. Res. Int. J. Folk. Ethnomusicol. 2015, 52, 143-156. [CrossRef]

8. Paddock, C.; Schofield, J. Authenticity and adaptation: The Mongol Ger as a contemporary heritage paradox. Int. J. Herit. Stud. 2017, 23, 347-361. [CrossRef]

9. Ott, M.; Dagnino, F.M.; Pozzi, F. Intangible cultural heritage: Towards collaborative planning of educational interventions. Comput. Hum. Behav. 2015, 51, 1314-1319. [CrossRef]

10. Grant, C. Learning and teaching traditional music in Cambodia: Challenges and incentives. Int. J. Music Educ. 2017, 35, 5-16. [CrossRef]

11. Zhang, K.; Zhang, M.; Law, R.; Chen, X.; Wang, Q. Impact model of tourism production and consumption in Nanjing Yunjin: The perspective of cultural heritage reproduction. Sustainability 2020, 12, 3430. [CrossRef]

12. Cimbaljević, M.; Stankov, U.; Demirović, D.; Pavluković, V. Nice and smart: Creating a smarter festival-the study of EXIT (Novi Sad, Serbia). Asia Pac. J. Tour. Res. 2021, 26, 415-427. [CrossRef]

13. Grobar, L.M. Policies to promote employment and preserve cultural heritage in the handicraft sector. Int. J. Cult. Policy 2019, 25, 515-527. [CrossRef]

14. Kuščer, K.; Mihalič, T. Residents' attitudes towards overtourism from the perspective of tourism impacts and cooperation-The case of Ljubljana. Sustainability 2019, 11, 1823. [CrossRef]

15. Seraphin, H.; Ivanov, S.; Dosquet, F.; Bourliataux-Lajoinie, S. Archetypes of locals in destinations victim of overtourism. J. Hosp. Tour. Manag. 2020, 43, 283-288. [CrossRef]

16. Khomsi, M.R.; Fernandez-Aubin, L.; Rabier, L. A prospective analysis of overtourism in Montreal. J. Travel Tour. Mark. 2020, 37, 873-886. [CrossRef]

17. Parry, R. Recoding the Museum: Digital Heritage and the Technologies of Change; Routledge: London, UK, 2007. 
18. Selmanović, E.; Rizvic, S.; Harvey, C.; Boskovic, D.; Hulusic, V.; Chahin, M.; Sljivo, S. Improving accessibility to intangible cultural heritage preservation using virtual reality. J. Comput. Cult. Herit. (JOCCH) 2020, 13, 1-19. [CrossRef]

19. Pollock-Ellwand, N. Common ground and shared frontiers in heritage conservation and sustainable development: Partnerships, policies and perspectives. Int. J. Sustain. Dev. World Ecol. 2011, 18, 236-242. [CrossRef]

20. Giliberto, F.; Labadi, S. Harnessing cultural heritage for sustainable development: An analysis of three internationally funded projects in MENA Countries. Int. J. Herit. Stud. 2021, 1-14. [CrossRef]

21. Zhang, G.; Chen, X.; Law, R.; Zhang, M. Sustainability of heritage tourism: A structural perspective from cultural identity and consumption intention. Sustainability 2020, 12, 9199. [CrossRef]

22. The United Nations Educational, Scientific and Cultural Organization (UNESCO). The Representative List of the Intangible Cultural Heritage of Humanity. Available online: https:/ / ich.unesco.org/en/lists (accessed on 10 November 2008).

23. Maags, C.; Holbig, H. Replicating Elite Dominance in Intangible Cultural Heritage Safeguarding: The Role of Local GovernmentScholar Networks in China. Int. J. Cult. Prop. 2016, 23, 71-97. [CrossRef]

24. Massing, K. Safeguarding intangible cultural heritage in an ethnic theme park setting-the case of Bing-langgu in Hainan Province, China. Int. J. Herit. Stud. 2018, 24, 66-82. [CrossRef]

25. Skowron-Markowska, S.; Nowakowska, M. Chinese Destinations Related to Martial Arts Tourism from the UNESCO Perspective. Sustainability 2021, 13, 7581. [CrossRef]

26. Pritchard, A. Statistical bibliography or bibliometrics. J. Doc. 1969, 25, 348-349.

27. Henderson, M.; Shurville, S.; Fernstrom, K. The quantitative crunch: The impact of biblio-metric research quality assessment exercises on academic development at small conferences. Campus Wide Inf. Syst. 2009, 26, 149-167. [CrossRef]

28. Rousseau, R.; Egghe, L.; Guns, R. Becoming Metric-Wise: A Bibliometric Guide for Researchers; Chandos Publishing: Oxford, UK, 2018.

29. Bañales-Seguel, C.; Riquelme Maulén, W.; Álvez, A.; Habit, E. Scientific Landscape Related to Mapuche Indigenous Peoples and Wallmapu Territory. Sustainability 2002, 12, 7895. [CrossRef]

30. Chen, C. CiteSpace: A Practical Guide for Mapping Scientific Literature; Nova Science Publishers: Hauppauge, NY, USA, 2016; ISBN 978-1-53610-280-2.

31. Chen, C. CiteSpace II: Detecting and visualizing emerging trends and transient patterns in scientific lit-erature. J. Am. Soc. Inf. Sci. Technol. 2006, 57, 359-377. [CrossRef]

32. Chen, C. Mapping scientific frontiers: The quest for knowledge visualization. J. Doc. 2003, 59, 364-369. [CrossRef]

33. Chen, C. Information Visualization: Beyond the Horizon; Springer Science \& Business Media: New York, NY, USA, 2004.

34. Kabil, M.; Priatmoko, S.; Magda, R.; Dávid, L.D. Blue Economy and Coastal Tourism: A Comprehensive Visual-ization Bibliometric Analysis. Sustainability 2021, 13, 3650. [CrossRef]

35. Brandes, U. A faster algorithm for betweenness centrality. J. Math. Sociol. 2001, 25, 163-177. [CrossRef]

36. Su, Z.; Zhang, M.; Wu, W. Visualizing Sustainable Supply Chain Management: A Systematic Scien-tometric Review. Sustainability 2021, 13, 4409. [CrossRef]

37. Li, J.; Chen, C. CiteSpace: Text Mining and Visualization in Scientific Literature; Capital University of Economics and Business Press: Beijing, China, 2016.

38. Hou, X.L.; Tan, G.X.; Zhuang, W.J.; Tang, M. Research on Knowledge Management of Intan-gible Cultural Heritage Based on Linked Data. J. Libr. Sci. China 2019, 2, 88-108. [CrossRef]

39. Niu, A.J.; Yu, D.H. Development of Wushu Industry from the Angle of Cultural and Creative Industries. Sport Sci. Res. 2008, 1, 70-72.

40. Song, J.H. On the characteristics of intangible cultural heritage. Jiangxi Soc. Sci. 2006, 1, 33-37.

41. Adabre, M.A.; Chan, A.P.; Darko, A. A scientometric analysis of the housing affordability literature. J. Hous. Built Environ. 2021, 1-33. [CrossRef]

42. Zheng, Y.M. Selection of the legal protection path for sports intangible cultural heritage. J. Shandong Sport Univ. 2017, 3, 54-56. [CrossRef]

43. Duan, C.; Sun, Y. On the improvement of the protection policy of intangible cultural heritage. J. South-Cent. Univ. Natl. (Humanit. Soc. Sci.) 2017, 6, 62-67.

44. Huang, T.; Zheng, W.Q. Connotation and importance of community identity in intangible cultural heritage protection. J. Renmin Univ. China 2018, 1, 27-36.

45. Zong, C.Y. Innovative application of digital animation technology in intangible cultural heritage protection. Art Panor. 2018, 12, 116-117.

46. Yang, Y.L.; Gao, W.Z.; Li, L.; Wang, Q.Y. Community education path of inheritors of rural in-tangible cultural heritage. Adult Educ. 2020, 5, 47-50.

47. Ma, N. Study on the training model of inheritors of Tibetan Thangkha in the view of intangible cultural heritage. Tibet. Stud. 2017, 6, 89-98.

48. Zhang, W. A study on the positive interaction mode between the protection of intangible cultural heritage and tourism development of ethnic minorities in Yunnan. Guangxi Ethn. Stud. 2020, 5, 127-133.

49. Chen, Y.; Ling, Y.P. On Tourism Development of Marine Intangible Cultural Heritage in Guangxi Beibu Gulf Area Based on RMP Analysis. Soc. Sci. Guangxi 2018, 6, 62-65. 
50. Wang, L.N.; Ning, D.; Li, W.G. Research on the integrated development of intangible cultural heritage and rural tourism-Taking Fushun Xinbin Manchu Autonomous County as an example. Agric. Econ. 2020, 7, 61-62.

51. Xiao, Y.P.; Wang, W.J. Research on "Xijiang Pattern": A case of intangible cultural heritage helps to boost rural vitalization. Cult. Herit. 2019, 3, 23-28.

52. Zhang, H.; Sun, J.X. Cultural Reproduction of Intangible Cultural Heritage Tourism Products: A Case Study of Miao Embroidery. J. North Minzu Univ. (Philos. Soc. Sci.) 2021, 1, 53-59.

53. Wang, Y.; Hu, H.L. Cultural identity: The core mechanism of the existence and development of in-tangible cul-tural heritage. Fujian Trib. (Humanit. Soc. Sci.) 2014, 10, 49-55.

54. Liu, B. Research on the protection of intangible cultural heritage of ethnic minorities in Hei-longjiang-From the perspective of rural revitalization. Heilongjiang Natl. Ser. 2019, 6, 142-146. [CrossRef]

55. Dong, H.A.; Ding, L. Study on the development and protection of the intangible cultural her-itage tourism in minority rural areas from the perspective of industrial convergence-a case study of Jingning She ethnic group county. Chin. J. Agric. Resour. Reg. Plan. 2019, 2, 197-204.

56. Wang, X.M.; Li, H. Research on the digital communication strategy of Heilongjiang's intangible cultural herit-age-from the perspective of "Internet plus". Heilongjiang Natl. Ser. 2019, 2, 88-93. [CrossRef]

57. Li, Y.L.; Zeng, Y.C. Industry and digital: A Study on the productive protection of intangible cultural heritage of Qiannan ethnic minorities. J. South-Cent. Univ. Natl. (Humanit. Soc. Sci.) 2017, 4, 64-68.

58. Tang, D.X.; Wu, M.Y. Productive protection of intangible cultural heritage: Connotation, problem presentation and theoretical reflection-Take Xuan paper as an example. Cult. Herit. 2017, 6, 9-15.

59. Wang, J.Y. Research on the entrepreneurial road of traditional craft intangible cultural heritage under the mode of productive protection-Taking Yongchuan Douchi as an example. China Condiment 2018, 5, 171-174.

60. Song, J.H. Cultural production and productive protection of intangible cultural heritage. Cult. Herit. 2012, 1-5+157.

61. The State Council of the PRC. Opinions on Strengthening the Protection of Intangible Cultural Heritage of China. Available online: http:/ /zwgk.mct.gov.cn/zfxxgkml/zcfg/gfxwj/202012/t20201204_906065.html (accessed on 26 March 2005).

62. Liu, L.L. Industrialization management of intangible cultural heritage-the combination of ethnomusicology and cultural industry. Big Stage 2012, 6, 285-286. [CrossRef]

63. Lü, G.W. Research on the sustainable development of intangible cultural heritage from the perspective of cul-tural and creative IP-Taking Wuxi embroidery as an example. Art Sci. Technol. 2018, 9, 45.

64. He, X.L.; Niu, J.M. Application of 3D digital technology in the intangible cultural herit-age protection: Taking Zhaoqing Duan ink stone as the example. Hundred Sch. Arts 2016, 231-233.

65. Li, J. Animation communication strategy of intangible cultural heritage "Liu Sanjie ballad". Media 2018, 22, 72-74.

66. Ministry of Culture of the PRC, the Ministry of Finance of the PRC, Ministry of Industry and Information Technology of the PRC. Revitalization Plan of Chinese Traditional Crafts. Available online: http:/ /www.gov.cn/xinwen/2017-03/27/content_5181257. htm (accessed on 27 March 2017).

67. The State Council of the PRC. Guiding Opinions of the State Council on Vigorously Advancing the "Internet Plus". Available online: http:/ / www.gov.cn/zhengce/content/2015-07/04/content_10002.htm (accessed on 1 July 2015).

68. Li, T.C.; Wang, J.H. A Review of Intellectual Property Protection Research on Intangible Cultural Heritage in China. Inf. Stud. Theory Appl. 2017, 3, 126-131. [CrossRef]

69. Jie, X.N.; Long, W.; Lv, Y. Certification of origination of intellectual property enables the original protection and living development of intangible cultural heritages. J. Nanjing Arts Inst. (Fine Arts Des.) 2020, 4, 159-162.

70. Liu, X.N. Intellectual Property Protection in Employing the Intangible Cultural Heritage in China. Hebei Law Sci. 2012, 11, 124-132. [CrossRef]

71. Chen, Y.Q. Thoughts on the construction of intellectual property database of Chinese art in-tangible cultural heritage in the context of "One belt, one road". Sichuan Drama 2019, 12, 50-54.

72. Liu, X.S. The experience, dilemma and countermeasure of inheritance and protection of sports in-tangible cultural heritage in China. Sports Cult. Guide 2019, 10, 63-68.

73. Yin, D.; Shi, B.; Chen, X.R. Spatial Distribution of Sports Intangible Cultural Heritage Tourism Re-sources in China-Based on GIS Spatial Analysis. J. Beijing Sport Univ. 2018, 11, 116-122. [CrossRef]

74. Wang, H.T. Research on the international communication of Chinese sports intangible cultural her-itage under the "One Belt and One Road" strategy. J. Guangzhou Sport Univ. 2018, 3, 36-39. [CrossRef]

75. Yan, Y.; Li, X.J. Research on protection and dissemination of Xinjiang ethnic minority sports intangible cultural heritage under the horizon of "the Belt and Road Initiative". J. Guangzhou Sport Univ. 2019, 6, 48-54. [CrossRef]

76. Yang, S.S. A Study on the Living Inheritance of Sports Intangible Cultural Heritage in the Villages with Ethnic Characteristics of Guangxi-Yunnan-Guizhou-Based on the Perspective of Cultural and Ecological Space Protection. Soc. Sci. 2019, 10, 90-96.

77. Ministry of Culture and Tourism, Measures for the Administration of National Eco-cultural Protection Zones. Available online: http:/ /www.gov.cn/xinwen/2018-12/25/content_5352070.htm (accessed on 10 December 2018).

78. Huang, Y.L. Cultural Heritage. Rural cultural revitalization and the protection and utiliza-tion of ICH: Based on rural development data analysis. Cult. Herit. 2019, 3, 1-12. 
79. Qin, J.Y.; Jia, R. Innovative Design of Artificial Intelligence in Intangible Cultural Heritage: Take Cloisonné as an Example. Packag. Eng. 2020, 6, 1-6. [CrossRef]

80. Gao, S.; Tan, G.X. Research on the Paradigm Shift of Intangible Cultural Heritage Management Driven by Big Data. Libr. City Country 2020, 76-82.

81. Yao, Z.W.; Di, J. The innovation of traditional handicraft in the context of intangible cultural heritage protection-Taking crewel embroidery as an example. J. Hubei Minzu Univ. (Philos. Soc. Sci.) 2020, 2, 101-106. [CrossRef]

82. Qian, Y.P. On the combination of productive protection of intangible cultural heritage and inclusive economic development-A case study of lingshang embroidery in Shanxi Province. Cult. Herit. 2019, 1, 20-25.

83. Qian, Y.P. Sustainable Development: A New Idea of the Safeguarding of Intangible Cultural Heritage in China. Cult. Herit. 2018, $3,8-14$.

84. Zhu, G. From "society" to "community": Definition of intangible cultural heritage subject moving towards openness. Natl. Arts 2017, 5, 42-49. [CrossRef]

85. An, D.M. The activity and heterogeneity of intangible cultural heritage community: A case study of villagers' interaction in the process of folk belief reconstruction in Jieting village. J. Yunnan Norm. Univ. (Humanit. Soc. Sci. Ed.) 2017, 6, 74-82.

86. Zhang, D. Community participation, community absence or communitarianism-The main dilemma of intangi-ble cultural heritage protection of Hani ethnic group. Northwest. J. Ethnol. 2018, 2, 33-42. [CrossRef]

87. The Report of the 19th National Congress of the Communist Party of China. Available online: https://www.spp.gov.cn/tt/2017 10/t20171018_202773.shtml (accessed on 18 October 2017).

88. Tai, X.N. Protection and inheritance of intangible cultural heritage in ethnic areas of frontier areas in the per-spective of cultural confidence. J. Yunnan Inst. Social. 2018, 1, 68-72.

89. Cai, H.B. From cultural loss to cultural confidence: Protection and development of intangible cultural heritage of ethnic dance. Guizhou Ethn. Stud. 2019, 2, 77-81. [CrossRef]

90. Santa Cruz, F.G.; Lopez-Guzman, T.; Gallo, L.S.P.; Rodríguez-Gutiérrez, P. Tourist loyalty and intangible cul-tural heritage: The case of Popayán, Colombia. J. Cult. Herit. Manag. Sustain. Dev. 2019, 10, 172-188. [CrossRef]

91. López-Guzmán, T.; Santa-Cruz, F.G. Visitors' experiences with Intangible Cultural Heritage: A case study from Córdoba, Spain. J. Herit. Tour. 2017, 12, 410-415. [CrossRef] 